\title{
REMOTE SENSING ANALYSIS OF THE CHANGES IN VEGETATED COASTLAND: THE CASE OF SOUTHEASTERN EUROPE
}

\author{
K. Laze*1 \\ ${ }^{1}$ Faculty of Civil Engineering, Polytechnic University of Tirana, Albania - kuendalaze@gmail.com
}

KEY WORDS: Classification, Coastland, Data error, Land change, Remote sensing, Vegetation, Southeastern Europe.

\begin{abstract}
:
The coastlands are changing in the Southeastern European countries. Yet, temporal and spatial changes in natural-vegetated land, urban-vegetated land and agriculture-vegetated land use on coastal surfaces, respectively, are missing. The aim is to understand the changes in vegetated land on the coastal surface by retrieving spatial data from remote sensing using a new approach by reducing errors in data processed and by collecting data using surveys to understand the driving (abiotic and biotic) factors of vegetated land changes and land dynamics at regional level. These spatial and survey data are then to be employed at spatially explicit analysis to define driving factors, plausibly explaining spatial and temporal changes of vegetated land on coastal surfaces in the Southeastern European study region including Albania, Bosnia and Herzegovina, Croatia, and Montenegro and Slovenia for the last fifty years. The expected main result is a new methodological approach of remote sensing spatial data analysis by reducing data errors and by identifying driving factors of the changes in vegetated land. The findings may serve to understand the effects of land management and land use on the changes in vegetated land-use on coastal surfaces, and to potentially uncover the least disturbed vegetated land areas by human intervention for vegetation conservation.
\end{abstract}

\section{INTRODUCTION}

The low-lying coastlands are threatened by unsustainable use, by the future climate change consequences based on the findings of the International Panel of Climate Change (IPCC) and by the future species extinction and biodiversity loss (IPBES). The changes in land cover and use on the coastal surface is occurring in many parts of Southeastern European countries, while coastlands are of high importance for vegetation biodiversity. There are studies on the changes in forest cover for some Southeastern European countries and on the effects of the changes in forest cover on the species habitats. Yet, temporal and spatial changes of the changes in natural-vegetated land, urban-vegetated land and agriculture-vegetated land use, respectively, are lacking for the entire study region. The aim is to understand the changes in vegetated land on the coastal surface at regional level by retrieving spatial data from remote sensing using a new approach reducing errors in data processed. These spatial data can be used for the spatially explicit analysis to define factors that plausibly explain spatial and temporal changes of vegetated land in the Mediterranean coastal study region in Southeastern Europe including Albania, Bosnia and Herzegovina, Croatia, and Montenegro and Slovenia. An innovative integrated database can be composed of remote sensing data updating classification data for the study area. These new data can further be analysed using well-established regression-based modelling and the most relevant modelling to explain spatial and temporal landscape dynamics for the last fifty years. The expected main result is a new methodological approach of remote sensing spatial data analysis. It is aimed to classify vegetated land into the natural vegetation, urban vegetation and vegetated-agricultural land use reducing errors in data. The findings may serve to understand the effects of land management and land use on the changes in vegetated land-use on coastal surfaces, which can be investigated as potential biodiversity metrics in terms of natural and semi-natural plants and forests. Any potential biotic interactions between vegetation communities and potential effects of climate on vegetation are expected to be revealed (e.g., Chauvier et al. 2020).

\section{METHOD}

The research objectives are to identify the changes in vegetated land, separating natural vegetation from urban vegetation and vegetated-agricultural land and then to identify dynamics of vegetated land changes and of driving factors explaining these changes in the coastal area of $61,637 \mathrm{~km}$ square (coastal area is in black colour line) presenting $41 \%$ of the entire study region (including Slovenia, Croatia, Bosnia and Herzegovina, Montenegro and Albania) (Figure 1) for the last fifty years. The research question is as follows: What are the dynamics of vegetated land systems in the Southerneastern Europe region? This research relies on collecting data of high resolution from remote sensing images (like Sentinels, Landsat, LiDAR, etc.), analysing them using new methods for reducing errors in data processed, and testing these data in a spatial statistical analysis of vegetated land cover.

\subsection{Agricultural and urban land}

This study retrieves spatial information needed for this study from remote sensing using "new approach for the semi-automatic verification" that has been used for agricultural land (cropland and grassland) "using mono-temporal very high resolution (VHR) multispectral satellite images; this "approach consists of two steps: first, a supervised pixel-based classification based on a Markov Random Field is employed to extract image regions. which contain agricultural areas" (Helmholz et al. 2014).

Optical Sentinel time series can be used to derive metrics capturing the variability over time for various parts of the electromagnetic spectrum i.e., visible light, near and shortwave 
infrared (Haberl et al. 2021) for urban areas. Night-time lights from Earth-observing (EO) satellites and OpenStreetMap may help classify buildings and small flat infrastructure (Haberl et al., 2021) e.g., roads from trees and green areas in urban areas. Conditional Random Field (CRF) approach may be used for urban objects like building (Niemeyer et al. 2012), Table 1. Machine learning applications can also be used for analysing optical and radar time series data of urban and agricultural areas (e.g., Rufin et al. 2019). The Normalized Difference Vegetation Index (NDVI, Tucker, 1979) and Tasseled Cap Greenness (Crist, 1985) can be applied for analysing urban vegetation (e.g. Frantz et al. 2021).

\subsection{Natural and semi-natural vegetation}

Remote sensing e.g., Landsat satellite images are widely used for (natural) vegetation analysis (Roy et al. 2016). Environmental (abiotic) variables related to soil water availability, evaporative demand and incident radiation, distance to stream and precipitation shape the distribution of plant communities (Schneider et al. 2020). Abiotic factors (elevation, slope, aspect, Terrain Ruggedness Index) and Normalised Difference Vegetation Index (NDVI) biotic factor are commonly used for analysing natural (and semi-natural) vegetation distribution.

The spatial statistical analysis may be generalized linear models (Burnham and Anderson 2002) that investigates temporal patterns of the vegetated land changes and Random Forests (Liaw and Wiener, 2002).

\subsection{Potential driving factors of vegetated land change}

The validity of the hypotheses of important driving factors of land change may be investigated in the study region. Expansion of urban and suburban, agricultural land and built-in infrastructure are hypothesized to be some of key driving factors of the changes in vegetated land i.e. reduced/increased vegetated land in the study area. However, heterogeneity of vegetated land change is also expected to be observed amongst five countries in the study area for the last fifty years.

There is a need to understand the causes (i.e., drivers, pressures) of (vegetation land) change and their interactions, to sustainably manage land cover (Gedefaw et al. 2020). Potential driving factors of vegetated land change can be investigated by using the framework of Drivers, Pressures, State, Impact, Responses (DPSIR) (e.g. Gabrielsen and Bosch 2003) to understand the driving factors of human interventions on coastlands. Potential driving factors of vegetated land change on coastlands in the study area might be increased human population in urban areas, expansion of urban areas and suburban areas, agricultural expansion/intensification (Geist and Lambin, 2002), infrastructure and policy/institutions (Lambin et al. 2001). Driving factors (pressures of DPSIR) may cause vegetated land cover change e.g., reduced forested land, increased agricultural land, higher rates of grassland to arable land conversion e.g., in Croatia (Cvitanović et al. 2017). Policy and institutional response could also be investigated using surveys in the study region. The period of fifty years may be set up to two or three periods to better investigate temporal changes of vegetation. The study can provide insights into temporal variations in the driving factors of vegetated coastlands and into the impact of region-level developments on coasts. The differential effects of land use and management policies on coasts can be inferred. Potential effects of climate on vegetation, e.g shifts of vegetation to higher elevation, can be revealed.

\subsection{Data}

Landsat $5 \mathrm{TM}$, Landsat $7 \mathrm{ETM}+$, and EO satellite imagery are key remote sensing fine scale data (from $10 \mathrm{~m} \times 10 \mathrm{~m}$ to $30 \mathrm{~m} \times$ $30 \mathrm{~m}$ ) for this study. Optical Copernicus Sentinel-2 sensors, radar Copernicus Sentinel-1 sensors from the European Commission's Copernicus program and crowd-sourced data (Open Street Map) are to produce high accuracy classification of human infrastructure (buildings, roads), trees and green areas in urban areas of the study region (Figure 1). Built-up data that were derived from Landsat images collections of the years 1975, 1990, 2000 and Landsat 8 collection of the years 2013/2014 can also be used as a built-up reference data (https://ghsl.jrc.ec.europa.eu/ghs_bu2019.php). Optical and radar Sentinel data can be combined for analysing urban and agricultural areas. The use of combined optical and radar data is far better (for urban areas) than the use of either optical or radar data sources (Frantz et al. 2021). Meroni et al. (2021) found that crop-specific land surface phenology (LSP) from Sentinel-1 and Sentinel-2 of major European crops were comparable to those of Sentinel-2, especially for winter crops.

Abiotic factors as elevation, slope, aspect, Terrain Ruggedness Index, can be derived from free fine scale Digital Elevation Model $(\mathrm{DEM})(30 \mathrm{~m} \times 30 \mathrm{~m})$ like ASTER Global Digital Elevation Map (https://asterweb.jpl.nasa.gov/gdem.asp). Topographic abiotic factors are commonly used in vegetation analysis. Normalised Difference Vegetation Index (NDVI) is a biotic factor to be derived from satellite images (e.g., Lannuzel et al. 2021).

In situ surveys of individual plants can be used, besides Landsat and EO satellite imagery. LiDAR data, national cadastral forest data and multi-spectral sensors data on drone platforms (e.g., Fawcett et al. 2020). Such data can be considered for this study, if these data are available.

\subsection{Fieldwork}

A set of surveys can be conducted to collect data about driving factors and pressures of DPRS framework (e.g. Gedefaw et al. 2020), and to collect in situ data of plants for conservation (see Lannuzel et al. 2021). Important Plant Areas that are hotspots of plant (and trees) conservation identified by International Union for Conservation of Nature (IUCN) can be potential areas for in situ plant data collection in the study region.

\subsection{Search for articles}

Peer-reviewed articles, published and unpublished documents like conference papers, academic reports, books, theses and reports on vegetation and vegetation land change in the study region can be retrieved using search platforms. The search for articles on urban vegetation, agricultural vegetation and natural and semi-natural vegetation include the Web of Science (http://apps.webofknowledge.com/), Scopus (http://scopus.com/), and the web-based search engine, Google Scholar (http://schol ar.google.com). 


\section{EXPECTED RESULTS AND DISCUSSION}

These changes in land cover on the coastland areas may indeed require good estimation studies at local level to uncover regional diversity of the changes in land cover and ecosystems considering that Southeastern European countries have a diverse, valuable biodiversity hotspots and undiscovered vegetation species (e.g. Dragičević et al. 2020). The rationale of this research is to develop a methodological approach meeting research objectives that are missing for the study region impeding a sustainable use of coastal land. This study can provide a methodological approach to use remote sensing for explaining the dynamics of vegetated land i.e. of natural vegetation, urban vegetation and agriculture-vegetated land use changes, and to identify a set of driving factors and variables that explain the vegetated land changes for the study region in Southeastern Europe. Fine scale data e.g., Sentinel 2A Copernicus Programme can be used for deriving vegetated land biodiversity metrics (using seasonal land changes) for the study region. Changes in trees and green areas can be produced for urban areas in the study region.

\subsection{Understanding driving factors}

The study region lacks studies on the distinct changes in vegetation cover on coastal surfaces. For example, Albania showed distinct changes in forested land in the western part (coastal area) of the country indicating a possible correlation between forest land (decreased) and urban and agricultural land (expanded) from 2000 to 2007 (Laze 2014). Changes in vegetation coastlands are expected to be calculated using remote sensing data and surveys on the ground. Remote sensing data and questionnaires were used to assess the changes in grassland, and to identify the driving factors as slope and altitude in land abandonment in Croatia (Cvitanović et al. 2017), to assess rates of the changes in forest cover between 1991 and 2011 in Croatia (Cvitanović et al. 2016), after the collapse of socialism. Calculations of remote sensing data are expected to show locations with the largest change (loss/gain) in vegetated land for the study region in the last fifty years. Surveys can help assess the perceptions of farmers, map their outcome and identify particularly driving factors, pressures and impacts of vegetated land change on the coastlands in the study region. Areas with the least disturbed vegetated land by human intervention for the last fifty years are expected to be uncovered. These areas could be potential areas for vegetation conservation.

\subsection{Potential vegetation conservation areas}

The study region is a biodiversity hotspot for plants in Europe (Figure 2). Priority areas for plant conservations are identified in Croatia (88), Slovenia (57), Albania (45) and Montenegro (8) (Anderson et al. 2005; Radford et al. 2011). Yet, this study can help provide new data on the distribution of vegetation species and on potential biotic interactions between vegetation communities in semi-natural and natural areas of the study region. Biotic interactions of plant communities are recently grown by using vegetation data, and or by the increasing interest in predicting unobserved (biotic) interactions including novel (plant) communities (Dormann et al. 2018). Fine scale data e.g., Copernicus 2A can help increase the accuracy of the water-land interface vegetation data. NASA's Global Ecosystem Dynamics Investigation (GEDI) can measure 3D plant canopy structure for Mediterranean ecosystems (Schneider et al. 2020). Vegetation simulations and field tests (Chiffard et al. 2020) can evaluate model evaluation. Finally, the evidence on the spatial patterns of land change, the processes of the conversion of vegetated land may be valuable for policy-makers, domestic organisations and for interactions of climate and biodiversity in Europe.

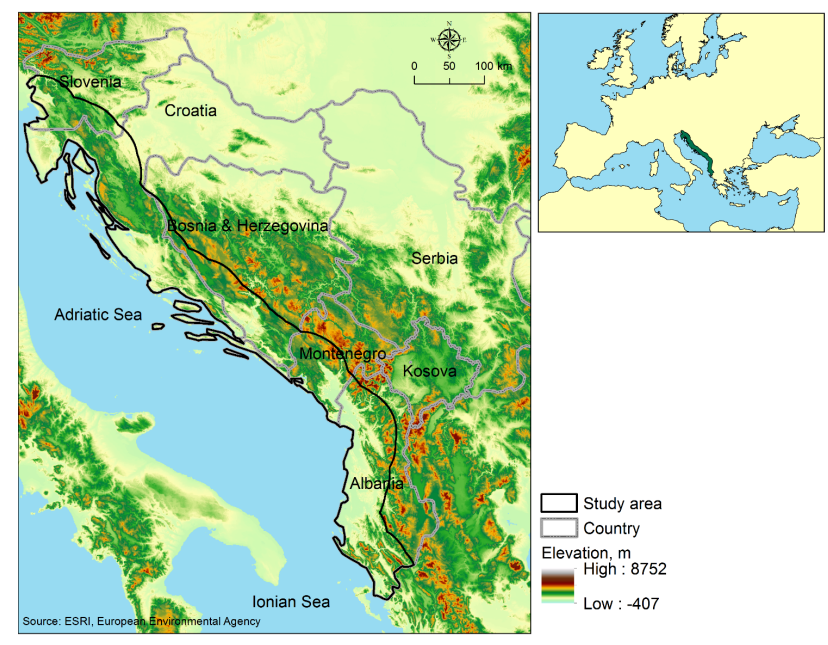

Figure 1. Study area.

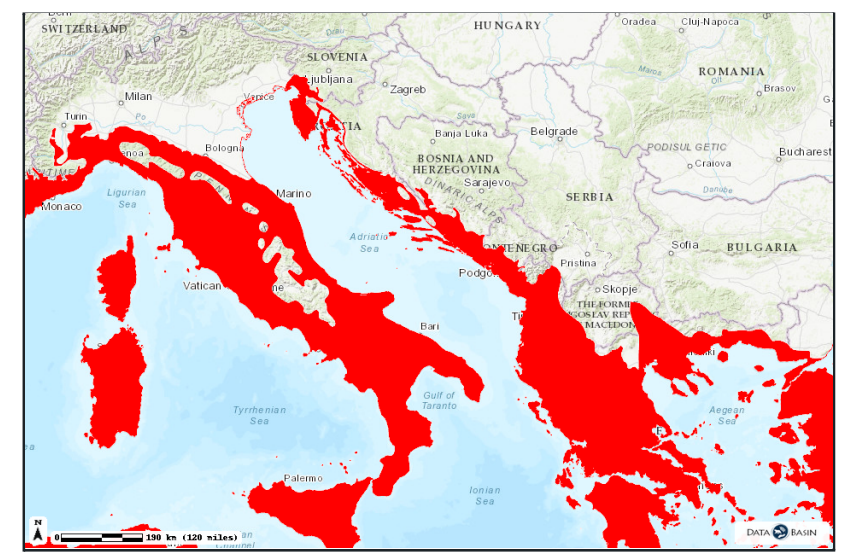

Figure 2. Biodiversity Hotspots Revisited, Conservation International, 2004. Hotspot area is in red colour.

\begin{tabular}{|l|c|c|}
\hline $\begin{array}{l}\text { Research } \\
\text { objectives }\end{array}$ & \multicolumn{2}{|c|}{ Methods - Expected results } \\
\hline $\begin{array}{l}\text { Established } \\
\text { a } \\
\text { methodologi } \\
\text { cal approach }\end{array}$ & $\begin{array}{c}\text { Support vector } \\
\text { machine } \\
\text { (SVM) } \\
\text { Conditional } \\
\text { Random Field } \\
\text { Identify the } \\
\text { dynamics of } \\
\text { vegetated } \\
\text { coastland } \\
\text { systems }\end{array}$ & $\begin{array}{c}\text { Assessed the } \\
\text { temporal and } \\
\text { spatial changes } \\
\text { in vegetated } \\
\text { land use }\end{array}$ \\
$\begin{array}{l}\text { Spatial } \\
\text { statistical } \\
\text { analysis of } \\
\text { vegetated land } \\
\text { (e.g., GLM, } \\
\text { Random } \\
\text { Forest) }\end{array}$ & $\begin{array}{c}\text { Identified } \\
\text { driving factors } \\
\text { of spatial } \\
\text { changes in } \\
\text { vegetated land } \\
\text { use }\end{array}$ \\
& $\begin{array}{c}\text { Survey (DPSIR } \\
\text { framework) }\end{array}$ & \\
& . & \\
\hline
\end{tabular}

Table 1. Research objectives, methods and expected results. 


\section{REFERENCES}

Anderson, S., Kušík,T., \& Radford, E. (Eds). (2005). Important Plant Areas in Central and Eastern Europe. Plantlife International.

https://www.plantlife.org.uk/application/files/8214/8233/1761/I PAsinCEE-5mb.pdf

Burnham, K. P., \& Anderson, D. R. (2002). Model selection and Multi-Model Inference. A practical information-theoretic approach, Springer-Verlag, New York, USA.

Chauvier, Y., Thuiller, W., Brun, P., Lavergne, S., Descombes, P., Karger, D. N., Renaud, J., \& Zimmermann, N. E. (2021). Influence of climate, soil, and land cover on plant species distribution in the European Alps. Ecological Monographs, 0(0), e01433. https://doi.org/https://doi.org/10.1002/ecm.1433

Chiffard, J., Marciau, C., Yoccoz, N. G., Mouillot, F., Duchateau, S., Nadeau, I., Fontanilles, P., \& Besnard, A. (2020). Adaptive niche-based sampling to improve ability to find rare and elusive species: Simulations and field tests. Methods in Ecology and Evolution, 11(8), 899-909. https://doi.org/https://doi.org/10.1111/2041-210X.13399.

Crist, E.P., 1985. A TM Tasseled Cap equivalent transformation for reflectance factor data. Remote Sens. Environ. 17, 301-306. https://doi.org/https://doi.org/10.1016/0034-4257(85)90102-6

Cvitanović, M., Lučev, I., Fürst-Bjeliš, B., Borčić, L.S., Horvat, S., Valožić, L., 2017. Analyzing post-socialist grassland conversion in a traditional agricultural landscape - Case study Croatia. J. Rural Stud. 51, 53-63. https://doi.org/https://doi.org/10.1016/j.jrurstud.2017.01.008

Cvitanović, M., Blackburn, G.A., Rudbeck Jepsen, M., 2016. Characteristics and drivers of forest cover change in the post-socialist era in Croatia: evidence from a mixed-methods approach. Reg. Environ. Chang. 16, 1751-1763. https://doi.org/10.1007/s10113-016-0928-0

Dormann, C. F., Bobrowski, M., Dehling, D. M., Harris, D. J., Hartig, F., Lischke, H., Moretti, M. D., Pagel, J., Pinkert, S., Schleuning, M., Schmidt, S. I., Sheppard, C. S., Steinbauer, M. J., Zeuss, D., \& Kraan, C. (2018). Biotic interactions in species distribution modelling: 10 questions to guide interpretation and avoid false conclusions. Global Ecology and Biogeography, 27(9), 1004-1016. https://doi.org/10.1111/geb.12759

Dragičević, S., Pöltl, M., Stabentheiner, E., \& Berg, C. (2020). Riccia atromarginata (Ricciaceae, Marchantiophyta) new to the west Balkan peninsula. Hacquetia, 20(1 SE-Articles), 49-56. https://ojs.zrc-sazu.si/hacquetia/article/view/8836

Fawcett, D., Bennie, J., Anderson, K., 2020. Monitoring spring phenology of individual tree crowns using drone-acquired NDVI data. Remote Sens. Ecol. Conserv. n/a. https://doi.org/https://doi.org/10.1002/rse2.184

Frantz, D., Schug, F., Okujeni, A., Navacchi, C., Wagner, W., van der Linden, S., Hostert, P., 2021. National-scale mapping of building height using Sentinel-1 and Sentinel-2 time series. Remote Sens. Environ. 252, 112128. https://doi.org/https://doi.org/10.1016/j.rse.2020.112128

Gabrielsen, P., Bosch, P., 2003. Environmental Indicators: Typology and Use in Reporting.
Gedefaw, A.A., Atzberger, C., Bauer, T., Agegnehu, S.K., Mansberger, R., 2020. Analysis of Land Cover Change Detection in Gozamin District, Ethiopia: From Remote Sensing and DPSIR Perspectives. Sustain. https://doi.org/10.3390/su12114534

Geist, H.J., Lambin, E.F., 2002. Proximate Causes and Underlying Driving Forces of Tropical Deforestation: Tropical forests are disappearing as the result of many pressures, both local and regional, acting in various combinations in different geographical locations. Bioscience 52, 143-150. https://doi.org/10.1641/0006-3568(2002)052[0143:PCAUDF]2. $0 . \mathrm{CO} ; 2$

Haberl, H., Wiedenhofer, D., Schug, F., Frantz, D., Virág, D., Plutzar, C., Gruhler, K., Lederer, J., Schiller, G., Fishman, T., Lanau, M., Gattringer, A., Kemper, T., Liu, G., Tanikawa, H., van der Linden, S., Hostert, P., 2021. High-Resolution Maps of Material Stocks in Buildings and Infrastructures in Austria and Germany. Environ. Sci. Technol. 55, 3368-3379. https://doi.org/10.1021/acs.est.0c05642

Helmholz, P., Rottensteiner, F., \& Heipke, C. (2014). Semi-automatic verification of cropland and grassland using very high resolution mono-temporal satellite images. ISPRS Journal of Photogrammetry and Remote Sensing, 97(0), 204-218.

https://doi.org/http://dx.doi.org/10.1016/j.isprsjprs.2014.09.008

Lannuzel, G., Balmot, J., Dubos, N., Thibault, M., Fogliani, B., 2021. High-resolution topographic variables accurately predict the distribution of rare plant species for conservation area selection in a narrow-endemism hotspot in New Caledonia. $\begin{array}{llll}\text { Biodivers. } & \text { Conserv. } & 30, & 963-990 .\end{array}$ https://doi.org/10.1007/s10531-021-02126-6

Lambin, E.F., Turner, B.L., Geist, H.J., Agbola, S.B., Angelsen, A., Bruce, J.W., Coomes, O.T., Dirzo, R., Fischer, G., Folke, C., George, P.S., Homewood, K., Imbernon, J., Leemans, R., Li, X., Moran, E.F., Mortimore, M., Ramakrishnan, P.S., Richards, J.F., Skånes, H., Steffen, W., Stone, G.D., Svedin, U., Veldkamp, T.A., Vogel, C., Xu, J., 2001. The causes of land-use and land-cover change: moving beyond the myths. Glob. Environ. Chang. 11 261-269. https://doi.org/10.1016/S0959-3780(01)00007-3

Meroni, M., d'Andrimont, R., Vrieling, A., Fasbender, D., Lemoine, G., Rembold, F., Seguini, L., Verhegghen, A., 2021. Comparing land surface phenology of major European crops as derived from SAR and multispectral data of Sentinel-1 and -2 . Remote Sens. Environ. 253, 112232. https://doi.org/https://doi.org/10.1016/j.rse.2020.112232

Niemeyer, J., Rottensteiner, F., \& Soergel, U. (2012). Conditional Random Fields for LiDAR Point Cloud Classification in Complex Urban Areas. ISPRS Ann. Photogramm. Remote Sens. Spatial Inf. Sci., I-3, 263-268. https://doi.org/10.5194/isprsannals-I-3-263-2012

Laze, K. (2014). Identifying and understanding the patterns and processes of forest cover change in Albania and Kosovo in Studies on the Agricultural and Food Sector in Transition Economies. In (IAMO), Leibniz Institute of Agricultural Development in Transition Economies. Studies on the Agricultural and Food Sector in Transition Economies (Vol. 74). Leibniz Institute of Agricultural Development in Transition 
Economies (IAMO). Vol. 74. ISBN 978-3-938584-78-1. http://www.iamo.de/dok/sr_vol74.pdf

Liaw, A., \& Wiener, M. (2002). Classification and Regression by randomForest. R News, 2(3), 18-22. https://doi.org/10.1177/154405910408300516.

Radford, E.A., Catullo, G. and Montmollin, B. de. (eds. . (2011). Important Plant Areas of the south and east Mediterranean region: priority sites for conservation. IUCN, Gland, Switzerland and Malaga, Spain. Gland, Switzerland and Malaga, Spain: IUCN. VIII +108 pp. https://portals.iucn.org/library/efiles/documents/2011-014.pdf

Roy, D.P., Kovalskyy, V., Zhang, H.K., Vermote, E.F., Yan, L., Kumar, S.S., Egorov, A., 2016. Characterization of Landsat-7 to Landsat-8 reflective wavelength and normalized difference vegetation index continuity. Remote Sens. Environ. 185, 57-70. https://doi.org/https://doi.org/10.1016/j.rse.2015.12.024

Rufin, P., Frantz, D., Ernst, S., Rabe, A., Griffiths, P., Özdoğan, M., Hostert, P., 2019. Mapping Cropping Practices on a National Scale Using Intra-Annual Landsat Time Series Binning. Remote Sens. . https://doi.org/10.3390/rs11030232

Schneider, F.D., Ferraz, A., Hancock, S., Duncanson, L.I., Dubayah, R.O., Pavlick, R.P., Schimel, D.S., 2020. Towards mapping the diversity of canopy structure from space with GEDI. Environ. Res. Lett. 15, 115006. https://doi.org/10.1088/1748-9326/ab9e99

Tucker, C.J., 1979. Red and photographic infrared linear combinations for monitoring vegetation. Remote Sens. Environ. 8 , $127-150$ https://doi.org/https://doi.org/10.1016/0034-4257(79)90013-0 